\title{
Shortening start-up and an extension of the power unit load range
}

\author{
Jan Taler ${ }^{1,}$, Marcin Trojan ${ }^{1}$, Dawid Taler $^{2}$, Piotr Dzierwa ${ }^{1}$ and Karol Kaczmarski ${ }^{1}$ \\ ${ }^{1}$ Institute of Thermal Power Engineering, Cracow University of Technology, Cracow, Poland \\ ${ }^{2}$ Institute of Thermal Engineering and Air Protection, Faculty of Environmental Engineering, \\ Cracow, Poland
}

\begin{abstract}
A power plant with additional water pressure tanks was proposed. The maximum rise in the block electric power resulting from the shut-off of low-pressure regenerative heaters was determined. At that time, the boiler is fed with hot water from water pressure tanks acting as heat accumulators. Accumulation of hot water in water tanks is also proposed in the periods of the power unit small load. In order to lower the plant electric power in the off-peak night hours, water heated to the nominal temperature in low-pressure regenerative heaters is directed from the feed water tank to pressure tanks. The water accumulated during the night is used to feed the boiler during the period of peak demand for electricity. Pressure accumulators are proposed to be used for the rapid start-up of the boiler from a cold state. The evaporator of the boiler is filled at the beginning of start-up with hot water from the accumulators. Drops in the power block electric power were determined for different capacities of the tanks and periods when they are charged. The tanks may also be used to ensure a sudden increase in the electric power of the unit that is operating in the automatic system of frequency and power control (in Polish: ARCM).
\end{abstract}

\section{Introduction}

Large oscillations occur in electric power generation due to the development of photovoltaic cells, wind farms and other distributed energy sources. Electricity should be supplied as soon as possible to the power grid by the thermal power units, during the power shortage that occurs in the electric power system. A requirement is also imposed on state-of-the-art power units to make it possible to raise or lower the power capacity at the rate of $2 \div 8 \%$ of installed power per minute in the full range of control, i.e. from the minimum to the maximum load. The power unit start-up from different states should also proceed fast.

The manufacturer of modern power units is obliged to carry out the following tests:

- Start-up from the cold state (after 8 hours of unit standstill)

- Start-up from the hot state (after 8 to 50 hours of unit standstill)

- Start-up from the cold state (after more than 50 hours of unit standstill)

The aim this article is an analysis of the possibility of using hot water pressure tanks to improve a $200 \mathrm{MW}$ power unit flexibility.

\footnotetext{
* Corresponding author: taler@mech.pk.edu.pl
} 
The water pressure tanks may be used to reduce the power unit power capacity in the off-peak night hours, due to low demand for electricity. In this, the period of low demand for electricity the boiler may operate at the minimum permissible load (at the level of the boiler technical minimum) then the steam is used both to generate electrical energy and to heat up hot water accumulated in the tanks.

In the period of peak demand for electricity, which in Poland is between 4 p.m. and 10 p.m., the power unit power capacity may be raised. Low-pressure regenerative bleeds are then shut off, which involves a rise in the electric power of the block due to a bigger mass flow rate of steam through the turbine. Hot water accumulated in the tanks is used for feed the boiler.

The water pressure tanks may also be used to fill the boiler with hot water at the beginning of the boiler start-up. According to the boiler drum optimum heating method proposed in [1-3], the boiler evaporator together with the drum may be filled with hot water with a temperature much higher than the initial one. Hot water accumulated in the pressure tank may be used to feed the bottom headers of the boiler furnace chamber walls, and the water displaced from the boiler evaporator may be directed to the bottom part of the pressure tank. Owing to such heat accumulators, the boiler start-up from the cold state becomes faster and safer.

Hot water pressure tanks may also be used in the automatic system of frequency and power control (ARMC) to ensure a sudden increase in the electric power of the power unit. It is possible to raise the maximum power capacity of the power unit by more than $7 \%$ for several hours feeding the boiler with hot water from the tanks. In order to rise rapidly maximum power capacity, low-pressure regenerative bleeds are shut off and the boiler is fed with hot water from the tanks.

Diagram of the power unit with a hot water storage tank used in the period of peak demand for electricity and low demand for electricity is shown in Figure 1.

a)

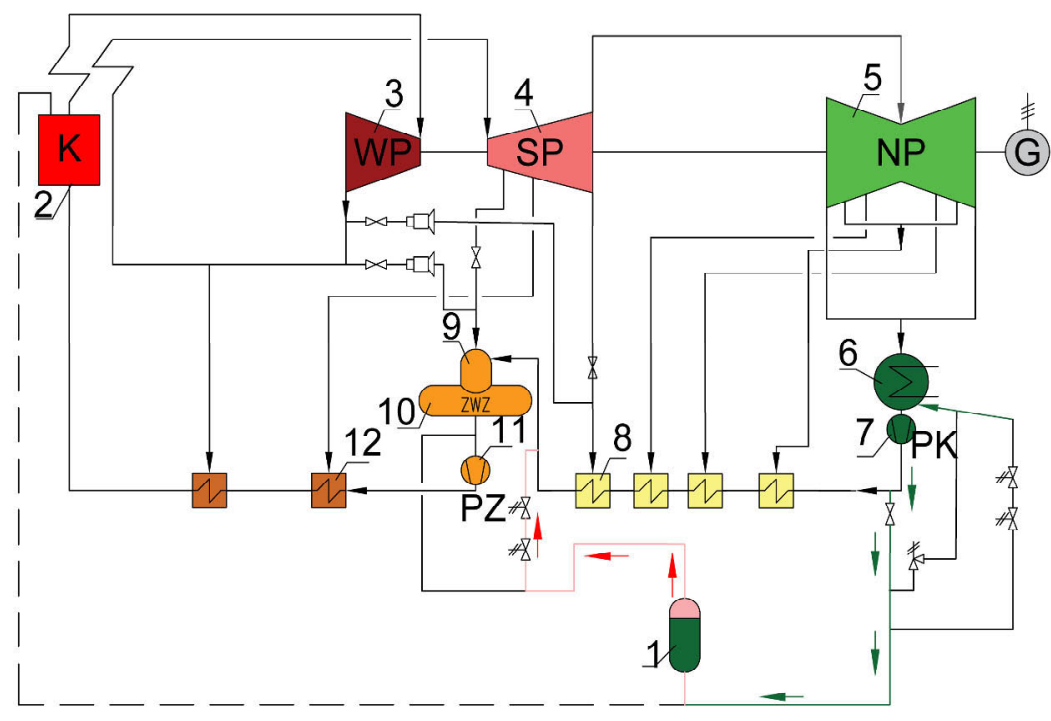


b)

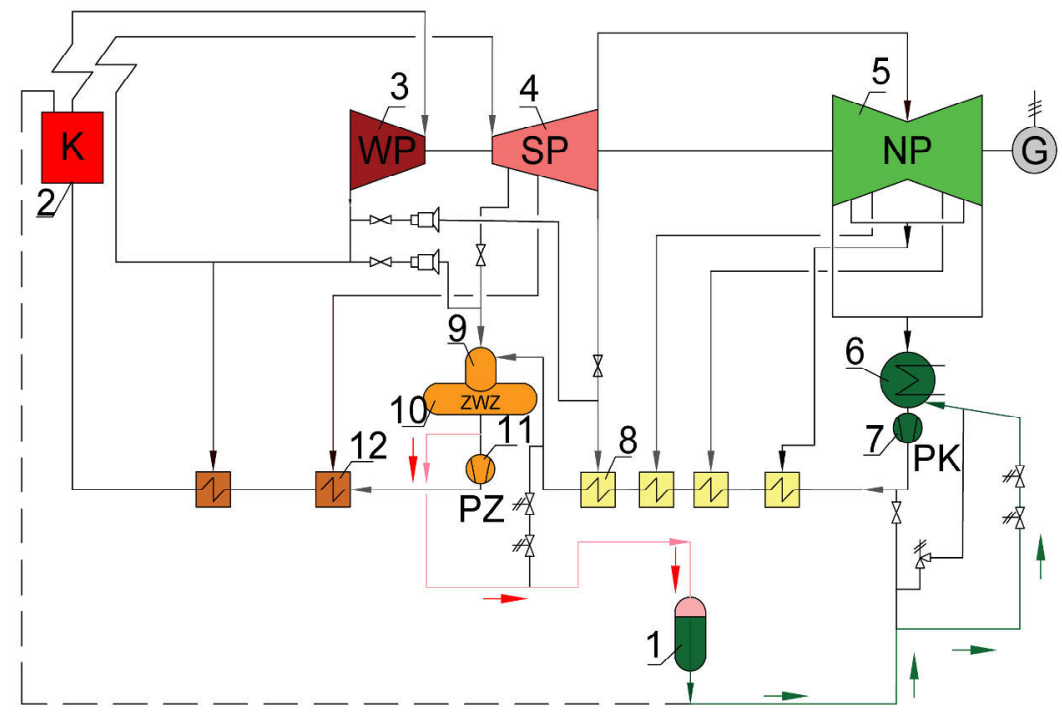

c)

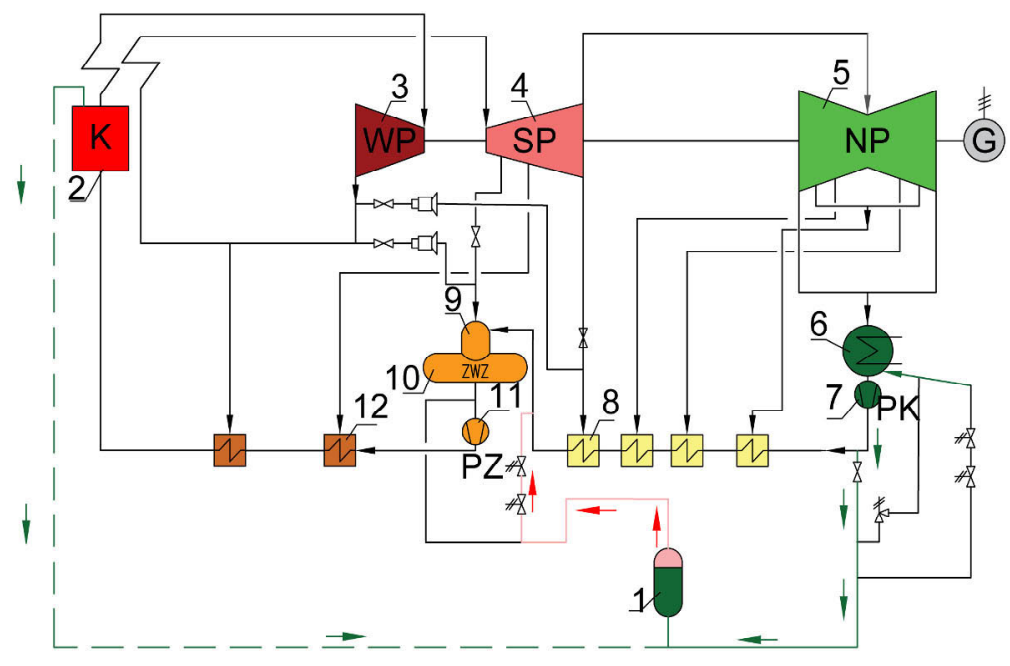

Fig. 1. Diagram of the thermal power plant with storage of hot water; a) rapid increase in the power block, b) reduction of the power block by filling the storage tank with hot water, c) rapid start-up of the boiler from the cold state by filling the boiler with hot water; 1 - heat storage tank, 2 - boiler, 3 - high pressure turbine, 4 - medium pressure turbine, 5 - low pressure turbine, 6 - condenser, 7 - condensate pump, 8 - low-pressure regenerative heaters, 9 - deaerator, 10 - feedwater tank, 11 - feedwater pump, 12 - high-pressure regenerative heaters.

In this paper, a mathematical model for an optimum heating the boiler evaporator with hot water is also presented. The power increase in the peak load using the water pressure tank and power reduction during the night by closing turbine bleeds are also calculated. 


\section{Analysis of using the water tanks to fill the evaporator with hot water}

Pressure tanks may be used to flood the boiler evaporator with hot water during the power unit start-up from the cold state (Fig. 1a). Filling the evaporator and then the drum with the initial temperature $T_{0}$ with hot water having temperature $T_{0}+\Delta T_{c z}$ (Fig. 2), the drum heating rate may be reduced in further stages of the start-up. The start-up time is only a bit shorter compared to the time obtained using the Standard PN-EN 12952-3, but in contrast to this standard, circumferential stress on the edge of the hole in the drum-downcomer junction does not exceed the permissible value [1-3].

If the boiler evaporator is heated at rates determined according to Standard PN-EN 12952-3 [4], permissible stress values are exceeded on a part of the hole perimeter [2]. This may quickly give rise to cracks on the downcomer tube hole edge. The method of the boiler start-up proposed in [1-3], where the boiler evaporator is filled with hot water, is safe. Unlike the Standard PN-EN 12952-3, the method allows an abrupt rise in the water temperature in the drum at the beginning of the drum heating process. The water temperature in the boiler drum may be raised even up to $100^{\circ} \mathrm{C}$, which makes it possible to reduce the consumption of heavy oil fired in the boiler. In the start-up first phase, the temperature of the water is raised to the nominal temperature of about $315^{\circ} \mathrm{C}$ from $100^{\circ} \mathrm{C}$ but not from $20^{\circ} \mathrm{C}$ to $315^{\circ} \mathrm{C}$.

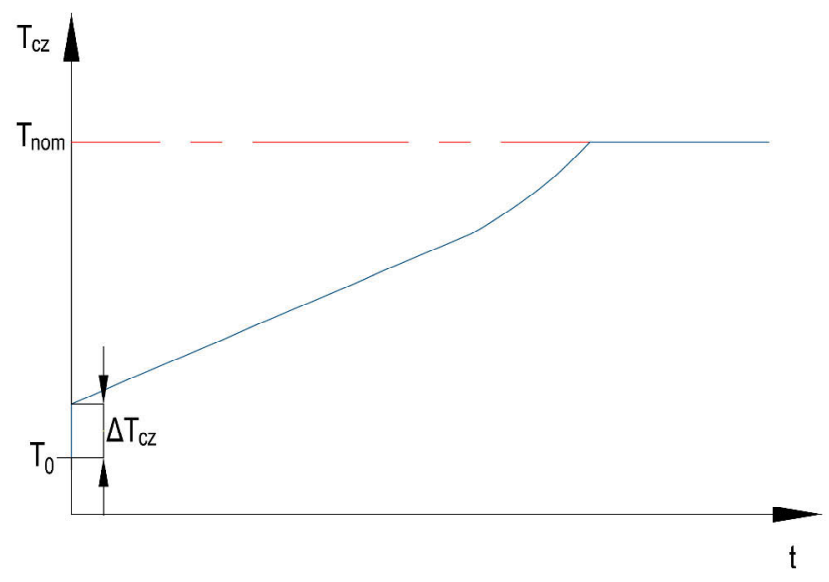

Fig. 2. Proposed optimum change in the temperature of the medium in the drum.

A mathematical model of the boiler evaporator was developed to determine the optimum value of the sudden temperature increase $\Delta T_{c z}$ in the feed water supplied to the boiler throguh lower headers of the evaporator so that the circumferential stress on the edge of the hole in the drum does not exceed the allowable stress.

Also, a steady- state mathematical model of the entire power block equipped with hot water storage tanks was developed to determine maximum power capacity increase during the peak loads and power decrease during nights when the demand for electrical energy is low. 


\section{Mathematical model of the boiler evaporator heating}

A scheme of water cooling and metal heating in the evaporator after it is suddenly filled with hot water in power unit with the capacity of 200MW is depicted in Fig. 3.

In order to simulate heating boiler evaporator, mathematical models of water walls and downcomers were developed. The cold air flows through the combustion chamber during evaporator heating. The outer surfaces of the downcomers are thermally insulated.

A differential form of the energy conservation equation for water flowing through the evaporator tubes and the energy conservation equation for the evaporator tube wall were derived first. After the formulation of all balance equations, a system of ordinary differential equations was solved using the finite difference method.

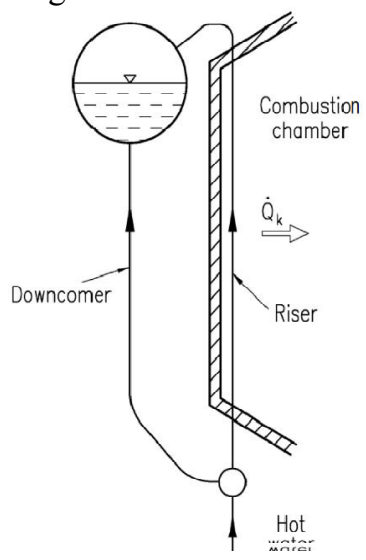

Fig. 3. Scheme of water cooling and metal heating in the evaporator after it is suddenly filled with hot water.

\subsection{Energy balance equation for water flowing through the evaporator and the riser tubes}

The energy balance equation for water flowing in the evaporator tube is

$$
\tau_{c} \frac{\partial T_{c}}{\partial t}+\frac{1}{N_{c}} \frac{\partial T_{c}}{\partial s^{+}}=-\left(T_{c}-T_{w}\right)
$$

where the number of transfer units for water $N_{c}$ and time constant of water $\tau_{c}$ are

$$
N_{c}=\frac{h_{w} \pi d_{w} L_{s}}{\dot{m}_{c} c_{c}} \text { and } \tau_{c}=\frac{d_{w}}{4 h_{w}} \rho_{c} c_{c}
$$

It was assumed that at the time $t=0$ the temperature of water in the evaporator tubes is constant and equal to ambient temperature $T_{o t}$, i.e. the initial condition is

$$
\left.T_{c}\right|_{t=0}=T_{o t}
$$

Hot water with temperature $T_{c g}$ flows into the riser tubes through lower headers to the boiler waterwalls and the boundary condition is of the following form

$$
\left.T_{c}\right|_{S^{+}=0}=T_{c g}
$$




\subsection{Energy balance equation for waterwall tubes}

The energy balance equation derived for a wall was derived assuming that the wall is an element with a lumped thermal capacity

$$
\tau_{w e} \frac{d T_{w}}{d t}+T_{w}=\frac{2 r_{w} h_{w} T_{c}+r_{z} h_{z r} T_{p o w}}{2 r_{w} h_{w}+r_{z} h_{z r}}
$$

where the time constant is given by

$$
\tau_{w e}=\frac{\left(r_{z}^{2}-r_{w}^{2}\right) \rho_{w} c_{w}}{2 r_{w} h_{w}+r_{z} h_{z r}}
$$

The value of the waterwall tube time constant (6) is highly dependent on the tube wall thickness and on the weighted heat transfer coefficient $h_{z r}$ on the air side, which is much lower than the heat transfer coefficient $h_{w}$ on the water side.

The initial condition for Equation (5) has the following form

$$
\left.T_{w}\right|_{t=0}=T_{o t}
$$

\subsection{Energy balance equation for air in the combustion chamber}

The energy balance equation for the air flowing upwards through the combustion chamber is

$$
\tau_{p} \frac{\partial T_{p}}{\partial t}+\frac{1}{N_{p}} \frac{\partial T_{p}}{\partial s^{+}}=\left(T_{w}-T_{p}\right)
$$

where the number of transfer units for air $N_{p}$ and time constant of air $\tau_{p}$ are

$$
N_{p}=\frac{n_{r} \pi r_{z} h_{z r} L_{s}}{\dot{m}_{p} c_{p}} \text { and } \tau_{p}=\frac{A_{k} \rho_{p} c_{p}}{n_{r} \pi r_{z} h_{z r}}
$$

The initial and the boundary conditions are, respectively

$$
\left.T_{p}\right|_{t=0}=T_{o t} \text { and }\left.T_{p}\right|_{s^{+}=0}=T_{o t}
$$

Similar energy conservation equation with appropriate boundry and initial conditions were formulated for downcomer tubes. The finite difference method was used to determine the water and air temperature as well as the temperature of the tube walls.

\section{Determination of the power capacity for the power unit while using heat storage tanks}

Mass flow rates and temperature of the water and the steam were determined from solving a system of equations of mass and energy balance set for all components of the thermal power plant. An example the control region for the boiler is shown in Fig. 4.

Figure 4 presents simplified diagram of the boiler with intake of injection water from outside the control region boundary used to write the mass and energy balance equations. 
The expressions for calculating the power of the turbine set in the night off-peak are given below:

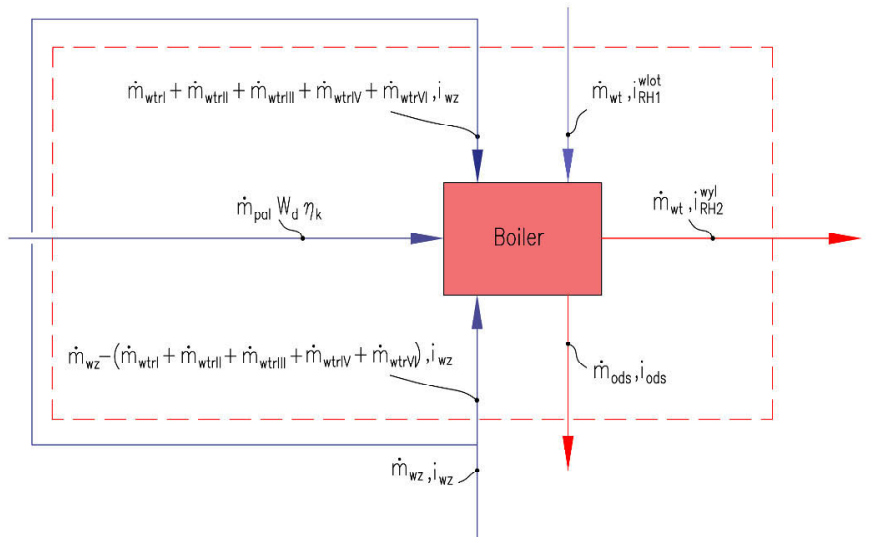

Fig. 4. Simplified diagram of the boiler

- internal power generated in a high-pressure part of the turbine set

$$
\dot{Q}_{w p}=\dot{m}_{p s}\left(i_{S H 5}^{w y l}-i_{I}\right)+\left(\dot{m}_{p s}-\dot{m}_{I}\right)\left(i_{I}-i_{I I}\right)
$$

- internal power generated in an intermediate-pressure part of the turbine set

$\dot{Q}_{s p}=\dot{m}_{s p}\left(i_{s p}-i_{I I I}\right)+\left(\dot{m}_{s p}-\dot{m}_{I I I}\right)\left(i_{I I I}-i_{I V}\right)+\left(\dot{m}_{s p}-\dot{m}_{I I I}-\dot{m}_{I V}\right)\left(i_{I V}-i_{V}\right)+$ $+\left(\dot{m}_{s p}-\dot{m}_{I I I}-\dot{m}_{I V}-\dot{m}_{V}\right)\left(i_{V}-i_{V I}\right)$

- internal power generated in a low-pressure part of the turbine set

$$
\dot{Q}_{n p}=\dot{m}_{n p}\left(i_{n p}-i_{V I I}\right)+\left(\dot{m}_{n p}-\dot{m}_{V I I}\right)\left(i_{V I I}-i_{z n p}\right)
$$

- the total internal power of the turbine set

$$
\dot{Q}_{t}=\dot{Q}_{w p}+\dot{Q}_{s p}+\dot{Q}_{n p}
$$

- the relative drop in the power unit related to the design power $\dot{Q}$

$$
\dot{Q}_{\text {proc }}=\frac{100 \dot{Q}_{t}}{\dot{Q}}
$$

- drop in power during the night off-peak hours

$$
S_{M}=100-\dot{Q}_{\text {proc }}
$$

The drop in the boiler output and in the power unit power in the night off-peak hours duringthe filling of the tank is shown Table 1. 
Table 1. List of results - the drop in the boiler output and in the power unit power in the night offpeak hours during the filling of the tank (power capacity $206 \mathrm{MW}$ ).

\begin{tabular}{|c|c|c|c|c|c|}
\hline Item & $\begin{array}{l}\text { Number } \\
\text { of tanks }\end{array}$ & $\begin{array}{l}\text { Time of filling } \\
\text { the tanks } \\
\text { during the } \\
\text { night off-peak } \\
\text { hours, } h\end{array}$ & $\begin{array}{c}\text { Water mass } \\
\text { flow to tanks, } \\
\text { t/h }\end{array}$ & $\begin{array}{l}\text { Boiler output } \\
\text { during the filling } \\
\text { of tanks, } t / h\end{array}$ & $\begin{array}{c}\text { Relative drop } \\
\text { in power, } \\
\%\end{array}$ \\
\hline 1 & \multirow{4}{*}{2} & 3 & 108.46 & 607.38 & 2.29 \\
\hline 2 & & 4 & 81.34 & 610.51 & 1.79 \\
\hline 3 & & 5 & 65.07 & 612.51 & 1.46 \\
\hline 4 & & 6 & 54.23 & 613.89 & 1.24 \\
\hline 5 & \multirow{4}{*}{4} & 3 & 216.91 & 596.99 & 3.96 \\
\hline 6 & & 4 & 162.67 & 601.80 & 3.19 \\
\hline 7 & & 5 & 130.15 & 605.05 & 2.66 \\
\hline 8 & & 6 & 108.46 & 607.38 & 2.29 \\
\hline 9 & \multirow{4}{*}{8} & 3 & 433.83 & 583.03 & 6.21 \\
\hline 10 & & 4 & 325.37 & 589.13 & 5.22 \\
\hline 11 & & 5 & 260.30 & 593.60 & 4.51 \\
\hline 12 & & 6 & 216.91 & 596.99 & 3.96 \\
\hline 13 & \multirow{4}{*}{12} & 3 & 650.75 & 574.21 & 7.63 \\
\hline 14 & & 4 & 488.06 & 580.46 & 6.62 \\
\hline 15 & & 5 & 390.45 & 585.30 & 5.84 \\
\hline 16 & & 6 & 325.37 & 589.13 & 5.22 \\
\hline
\end{tabular}

\section{Summary}

The results of the performed calculations and analyses indicate that installation of water pressure tanks is well justified. The investment is profitable. Water pressure tanks may not only be used to reduce the power unit power during the off-peak night hours and raise it in the periods of peak demand, but also to increase the power capacity fast at any time. Hot water tanks may also be used to fill the boiler with hot water at the beginning of the boiler start-up. According to the boiler drum optimum heating method proposed in [1-3], the boiler evaporator together with the drum may be filled with hot water at a temperature much higher than the initial one. The pressure hot water tank may be used to feed the bottom headers of the boiler furnace water walls. The cold water displaced from the boiler evaporator may be directed to the bottom part of the pressure tank. Owing to such heat accumulators, the boiler start-up from the cold state becomes faster and safer.

The results of the analysis of the 200 MW power unit thermal system and of the thermal calculations lead to the following conclusions:

1. The power unit maximum power capacity of $206 \mathrm{MW}$ may be raised in the period of peak demand for electricity by $7.32 \%(0.0732 * 206=15 \mathrm{MW})$

2. The period of the power unit operation with the raised maximum power capacity may last:

- 30 minutes at two tanks with the total capacity of $360.5 \mathrm{~m}^{3}$

- 60 minutes at four tanks with the total capacity of $721 \mathrm{~m}^{3}$

- 120 minutes at eight tanks with the total capacity of $1442 \mathrm{~m}^{3}$

- 180 minutes at twelve tanks with the total capacity of $2163 \mathrm{~m}^{3}$ 
3. The maximum reduction in the power unit power capacity (which is $135 \mathrm{MW}$ before the activation of the heat storage tanks) during the night off-peak hours is $16.27 \%(0.1627 * 135=21.96 \mathrm{MW})$ at eight tanks with the total capacity of 1442 $\mathrm{m}^{3}$. The period in which the tanks are charged, and consequently the time of the power unit operation under a reduced load, is 3 hours.

4. If eight water tanks with the total capacity of $1442 \mathrm{~m}^{3}$ are charged for 6 hours, the reduction in the power unit power capacity is $8.15 \%\left(0.0815^{*} 135=11 \mathrm{MW}\right)$. If the water pressure tanks are discharged during 2 hours in the period of peak demand for electricity, the increment in the power unit power capacity totals $7.32 \%$ (15 MW). This solution, which anticipates installation of 8 tanks charged for 6 hours during the night off-peak period and discharged for 2 hours in the peak period, is recommended to be used in practice.

5. The tanks may be made as vertical structures with stratification of cold and hot water and operating in a parallel system. The hot water tanks may also be horizontal. In this case, they operate as a series-parallel system.

6. Hot water pressure tanks may also be used in power units participating in the automatic system of frequency and power control (ARMC) to ensure a sudden increase in the power unit power at any time of the day.

In order to shorten the start-up from the cold state, the boiler evaporator may be flooded with hot water from one of the pressure water tanks.

\section{Nomenclature}

$c \quad-$ specific heat capacity at constant pressure, $\mathrm{J} /(\mathrm{kg} \cdot \mathrm{K})$

d - diameter, $\mathrm{m}$,

D - diameter, m,

$d_{w} \quad-$ inner diameter of the tube, $\mathrm{m}$

$\mathrm{G} \quad-$ generator,

$h \quad-$ heat transfer coefficient, $\mathrm{W} /\left(\mathrm{m}^{2} \cdot \mathrm{K}\right)$

$i \quad-$ specific fluid enthalpy, $\mathrm{kJ} / \mathrm{kg}$,

$i_{I} \quad-$ enthalpy of bleed I steam, $\mathrm{kJ} / \mathrm{kg}$

$i_{I I} \quad-$ enthalpy of bleed II steam, $\mathrm{kJ} / \mathrm{kg}$

$i_{I I I} \quad-$ enthalpy of bleed III steam, $\mathrm{kJ} / \mathrm{kg}$

$i_{I V} \quad-$ enthalpy of bleed IV steam, $\mathrm{kJ} / \mathrm{kg}$

$i_{V} \quad-$ enthalpy of bleed $\mathrm{V}$ steam, $\mathrm{kJ} / \mathrm{kg}$

$i_{V I} \quad-$ enthalpy of bleed VI steam, $\mathrm{kJ} / \mathrm{kg}$

$i_{V I I} \quad-$ enthalpy of bleed VII steam, $\mathrm{kJ} / \mathrm{kg}$

$i_{R H_{1}}^{\text {wlot }} \quad-$ steam specific enthalpy upstream the steam reheater stage $\mathrm{I}, \mathrm{kJ} / \mathrm{kg}$,

$i_{R H_{2}}^{w y l} \quad-$ steam specific enthalpy downstream the steam reheater stage II, $\mathrm{kJ} / \mathrm{kg}$,

$i_{n p} \quad-$ enthalpy of the steam flow to the turbine low-pressure part, $\mathrm{kJ} / \mathrm{kg}$

$i_{\text {ods }} \quad-$ specific enthalpy of brine, $\mathrm{kJ} / \mathrm{kg}$,

$i_{S H 5}^{w y l} \quad-$ specific enthalpy of the boiler live steam, $\mathrm{kJ} / \mathrm{kg}$,

$i_{s p}$

- enthalpy of the steam flow to the turbine intermediate-pressure part, $\mathrm{kJ} / \mathrm{kg}$ 
$i_{w z} \quad-$ specific enthalpy of feed water, $\mathrm{kJ} / \mathrm{kg}$,

$i_{z n p} \quad-$ specific enthalpy of the steam flow from the low-pressure turbine part, $\mathrm{kJ} / \mathrm{kg}$,

$L_{s} \quad-$ tube length, $\mathrm{m}$

$n \quad-$ number of tanks,

$N_{c}, N_{p} \quad-$ number of transfer units for water and air, respectively

$r_{w}, r_{z} \quad-$ inner and outer tube radius, $\mathrm{m}$

$s^{+} \quad-$ dimensionless curvilinear coordinate, $\mathrm{m}$

$t \quad-$ time, $\mathrm{s}$

$T_{c}, T_{p}, T_{w}$ - temperature of water, air, and riser tube wall, respectively, ${ }^{\circ} \mathrm{C}$,

$\dot{Q} \quad-$ heat flow rate, MW,

$W_{d} \quad-$ fuel calorific value, $\mathrm{kJ} / \mathrm{kg}$,

$\dot{m} \quad-$ fluid mass flow rate, $\mathrm{kg} / \mathrm{s}$,

$\dot{m}_{I}, \dot{m}_{I I}, \dot{m}_{I I I}, \dot{m}_{I V}, \dot{m}_{V}, \dot{m}_{V I}, \dot{m}_{V I I}-$ steam mass flow from bleed: I, II, III, IV,V, VI, VII,kg/s

$\dot{m}_{n p} \quad-$ steam mass flow to the turbine low-pressure part, $\mathrm{kg} / \mathrm{s}$

$\dot{m}_{p s} \quad$ - boiler output (live steam mass flow at the boiler outlet), $\mathrm{kg} / \mathrm{s}$

$\dot{m}_{s p} \quad-$ steam mass flow to the turbine intermediate-pressure part, $\mathrm{kg} / \mathrm{s}$

\section{Greek symbols}

$\begin{array}{ll}\eta_{k} & - \text { boiler efficiency. } \\ \rho & - \text { density, } \mathrm{kg} / \mathrm{m}^{3} \\ \tau_{c,}, \tau_{p}, \tau_{w e} & - \text { time constant of water, air, and riser tube, respectively, } \mathrm{s}\end{array}$

\section{References}

1. J. Taler, P. Dzierwa, D. Taler, P. Harchut, Energy, 92, 1 (2015) 160-170

2. P. Dzierwa, D. Taler, J. Taler, M. Trojan, "Optimum heating of thick wall pressure components of steam boilers", ASME 2014 Power Conference POWER2014, July 2831, 2014, Baltimore, Maryland, USA, p. 1-9

3. P. Dzierwa, J. Taler, J Press Vess-T ASME, 137 (2014) 011202-1-8

4. Polish Standard PN-EN 12952-3, "Kotły wodnorurowe i urządzenia pomocnicze. Część 3: Konstrukcja i obliczenia części ciśnieniowych [Water-tube boilers and auxiliary installations. Part 3: Design and calculation for pressure parts.], PKN [Polish Standardization Committee], Warszawa 2004 